\title{
Assessing the sleep quality and depression-anxiety-stress in irritable bowel syndrome patients
}

\author{
Nadieh BANIASADI ${ }^{1}$, Mohammad Moein DEHESH ${ }^{2}$, Elham MOHEBBI ${ }^{3}$, \\ Mahdy HAYATBAKHSH ABBASI ${ }^{2}$ and Zohreh OGHABIAN ${ }^{2}$
}

Received 18/9/2016 Accepted 16/1/2017

\begin{abstract}
Background - Irritable bowel syndrome (IBS) is one of the most common functional gastrointestinal disorders with chronic abdominal pain and altered bowel habit without any organic reason. Sleep disorders may be associated to IBS. Objective - We aimed to assess sleep disturbances and depression-anxiety-stress in IBS patients. Methods - In this analytical cross sectional study from November 2013 to May 2014 , A total of 123 IBS patients were recruited by simple random sampling. IBS was diagnosed using ROME-III criteria. Demographic and basic data were driven from all patients then Pittsburg Sleep Quality Index questionnaire was utilized to estimate sleep quality and DASS (depression anxiety stress scale) questionnaire was filled out for depression, anxiety and stress. Results - The mean age of patients was $29 \pm 9$, where 48 cases ( $39 \%)$ were male. Twelve cases $(10 \%)$ had a background disease. Types of IBS in patients were included $38 \%$ diarrhea, $42 \%$ constipation and $20 \%$ mixed. From all IBS patients 87 (71\%) cases had depression, $97(79 \%)$ patients stress, 94 (76\%) patients had anxiety. Seventy-six (62\%) cases of IBS patients had poor sleep quality. Simultaneously employing predictors demonstrate that gender, background disease, and type of IBS did not statistically significant. On the other hand, depression $(P=0.034, \mathrm{OR}=2.35)$, anxiety $(P=0.011, \mathrm{OR}=3.022)$, and stress $(P=0.029, \mathrm{OR}=2.77)$ were significantly effect on sleep quality in poor sleepers. Conclusion - Many of IBS patients is suffering from poor sleep quality. It seems that sleep disorder should be considered and treated in this patients. HEADINGS - Irritable bowel syndrome. Sleep wake disorders. Depression. Anxiety.
\end{abstract}

\section{INTRODUCTION}

Psychological disorders have an important role in many diseases like irritable bowel syndrome (IBS), widely involving individuals with any ethnicity and gender $(5 \%-20 \% \text { of general populations })^{(2,30)}$. It is often associated with other disorders, hence, the patient may have to undergo expensive tests and treatments, as a result the disease also compels burden to societies. On the other hand, IBS influence on patients' quality of life $\mathrm{e}^{(7,17,23,28,31)}$.

IBS is one of the most functional gastrointestinal disorders manifesting with cramping abdominal pain, discomfort and also defecation disorders (constipation and/or diarrhea) $15^{(15)}$. Onset of IBS is more likely to occur as a post infection disease or stressful life event, but other etiological factors are still unknown ${ }^{(6,29)}$.

Sleep disturbances is a common complaint in IBS patients causing some psychological disorders including neurosis, anxiety, and depression that are more prevalent in IBS patients correlated with sleep quality ${ }^{(3,4,8,14,16,18,26,28,)}$. High prevalence of sleep disturbances has been observed among IBS patients ${ }^{(9,24,27,32)}$, a remarkable increase in rapid-eye-movement (REM) sleep is the only unusual pattern demonstrated in the patients ${ }^{(11,25)}$.

Assessing sleep quality associated with the mentioned psychological disorders in IBS patients has been investigated in few studies $^{(20,24)}$, but the results are controversial whether poor sleep quality related to the underlying mood disturbances in IBS patients $^{(5,10)}$. The present study discuss existence of the association in the patients using the Pittsburgh Sleep Quality Index (PSQI) ${ }^{(19)}$ and depression anxiety stress scale (DASS) ${ }^{(1)}$ which Persian versions has been adapted and confirmed. Moreover, the severity of IBS, the obtained scores, and demographic features are also analyzed to explore interactions.

\section{METHODS}

A cross sectional study was carried out between November 2013 to May 2014. A total of 123 proved IBS patients (Rome III criteria) were recruited by convenience sampling from an academic hospital clinic and two private clinics. During the time of study all IBS patients were asked to fill DASS and PSQI Questionnaires, having taken informed consent.

Two trained nurses interviewed the participants about demographic features and explain instruction of the questionnaires. Then, depression, anxiety, stress and sleep quality information was collect via the self-administered questionnaire of DASS and PSQI.

PSQI has 19 questions and seven components including sleep quality, sleep latency, sleep duration, habitual sleep efficiency, and

Declared conflict of interest of all authors: none

Disclosure of funding: no funding received

Bam University of Medical Sciences, School of Medicine, Bam, Iran; ${ }^{2}$ Afzalipoor Research Center of Gastroenterology, Kerman University of Medical Sciences, Kerman, Iran; ${ }^{3}$ Research Center for Modeling in Health, Institute for Futures Studies in Health, Kerman University of Medical Sciences, Kerman, Iran.

Correspondence: Mohammad Moein Dehesh. Student Research Committee of Kerman University of Medical Sciences. Deputy of Research and Technology of Kerman University of Medical Sciences, Ebn-e-Sina St, Tahmasbabad Junction, Shariaty St., Kerman, Iran. E-mail: moeindehesh@gamil.com 
sleep disturbances, use of sleep medication, and daytime dysfunction over the last months. Poor sleep quality defined as score less than 5 globally while the total score is 21 . PSQI was translated to Persian and it was reported suitable questioner in Iranian population with acceptable validity and reliability ${ }^{(3,19)}$. The other one, DASS, composed of 42 questions to evaluate depression, anxiety and stress ${ }^{(1)}$.

Patients those had gastrointestinal symptoms were examined by a gastroenterologist. Proven diagnosis of IBS using ROME-III criteria was necessary. Patients with comorbidity of a psychiatric disorder or organic bowel disease and incomplete questionnaires were excluded.

\section{Statistical analysis}

Univariate logistic regression applied for evaluating the association between independent variables and sleep quality. Multivariate logistic regression was used to evaluate simultaneous effect of these variables on sleep quality. In another analysis depression, anxiety and stress divided into four severity grades to compare groups. $P$ value 0.05 was considered as statistical significance.

\section{RESULTS}

One hundred and twenty-three IBS patients were assessed. The mean age was $29.7 \pm 9.8$ and $39 \%$ was male. About $10 \%$ of cases had a background disease. Moreover, about $38 \%$ of patients were constipation dominant, $42.3 \%$ were diarrhea dominant and $19.5 \%$ suffered from mixed type (constipation-diarrhea). The majority of IBS patients had depression anxiety and stress (Table 1). Classification of DASS scores by its guideline showed that of 123 IBS patients, $70.72 \%$ had depression, $75.63 \%$ had anxiety, and $78.86 \%$ had stress.

TABLE 1. Demographic characteristics

\begin{tabular}{lc}
\hline Characteristic & Frequency $\mathbf{n}(\%)$ \\
\hline Gender & \\
Male & $48(39.0 \%)$ \\
Female & $75(61.0 \%)$ \\
Background disease & \\
Yes & $12(9.8 \%)$ \\
No & $111(90.2 \%)$ \\
IBS type & \\
Constipation & $47(38.2 \%)$ \\
Diarrhea & $52(42.3 \%)$ \\
Mixed & $24(19.5 \%)$ \\
Sleep quality & \\
Poor & $28(22.8 \%)$ \\
Good & $95(77.2 \%)$ \\
Depression & \\
Yes & $87(70.7 \%)$ \\
No & $36(29.3 \%)$ \\
Anxiety & \\
Yes & $94(76.4 \%)$ \\
No & $29(23.6 \%)$ \\
Stress & \\
Yes & $97(78.9 \%)$ \\
No & $26(21.1 \%)$ \\
\hline
\end{tabular}

IBS: irritable bowel syndrome
Moreover, severity of depression, anxiety, and stress in poor sleepers was extremely more than good sleepers (Table 2, Figure $1-3)$. Totally, seventy-six cases $(61.8 \%)$ of IBS patients had poor sleep quality.

TABLE 2. Severity of depression, anxiety and stress irritable bowel syndrome patients

\begin{tabular}{ll}
\hline Psychological condition & Frequency n (\%) \\
\hline Depression (123 persons) & \\
Normal & $36(29.3 \%)$ \\
Mild & $16(13.0 \%)$ \\
Moderate & $27(21.9 \%)$ \\
Severe & $21(17.1 \%)$ \\
Very severe & $23(18.7 \%)$ \\
& \\
Anxiety (119) & \\
Normal & $29(24.4 \%)$ \\
Mild & $12(10.1 \%)$ \\
Moderate & $17(14.3 \%)$ \\
Severe & $22(18.5 \%)$ \\
Very severe & $39(32.7 \%)$ \\
& \\
Stress (123) & \\
Normal & \\
Mild & $26(21.1 \%)$ \\
Moderate & $13(10.6 \%)$ \\
Severe & $21(17.1 \%)$ \\
Very severe & $40(32.5 \%)$ \\
\hline
\end{tabular}

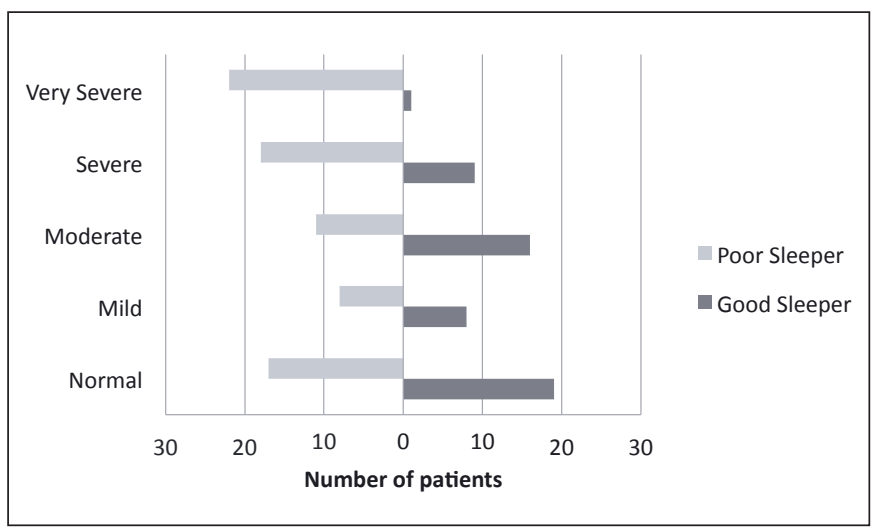

FIGURE 1. Severity of depression by quality of sleep

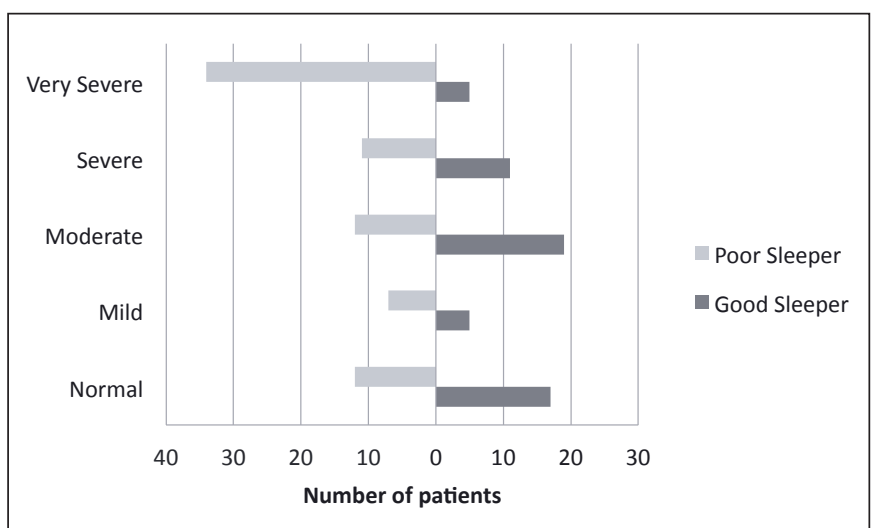

FIGURE 2. Severity of Anxiety by quality of sleep 


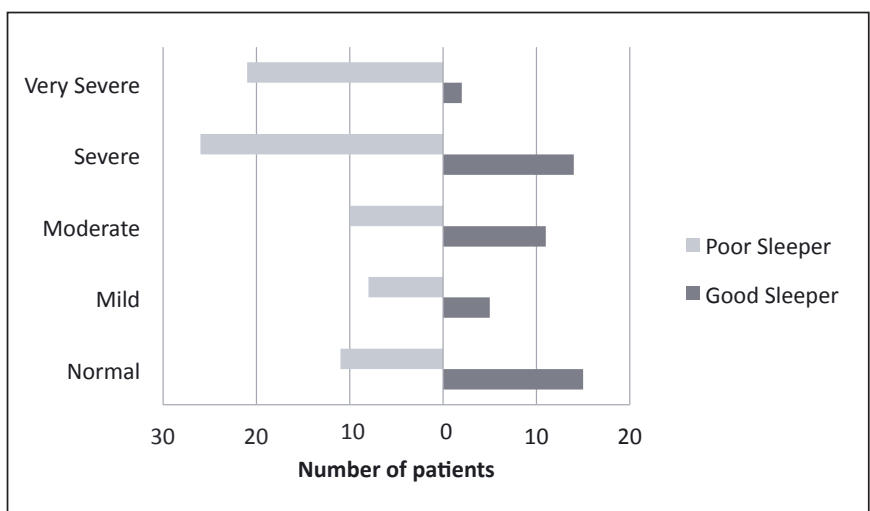

FIGURE 3. Severity of stress by quality of sleep

The sleep quality score in our patients ranged from 1 to 17 with the mean of $7.2 \pm 3.5$. Twenty-eight $(22.7 \%)$ were poor sleepers. There was no correlation between PSQI and type of IBS ( $\mathrm{r}=0.038$, $P=0.674)$.

Simultaneously employing predictors demonstrate that gender, background disease, and type of IBS did not statistically significant. On the other hand, depression $(P=0.034, \mathrm{OR}=2.35)$, anxiety $(P=0.011, \mathrm{OR}=3.022)$, and stress $(P=0.029, \mathrm{OR}=2.77)$ were significantly effect on sleep quality in poor sleepers.

\section{DISCUSSION}

Along with the aim of the study to assess sleep quality by utilizing depression, anxiety, and stress in IBS patients, majority of IBS patients suffered from poor sleep quality which fairly associated with the psychological conditions.

Poor sleep quality has been demonstrated in IBS patients; a Turkish studies has indicated that $36 \%$ of IBS patients were poor sleepers in compare with healthy volunteers (18\%) using PSQI ${ }^{(33)}$. However, the present study does not compare IBS patients with other groups, our participants were also $61.8 \%$ poor sleepers.

In Iranian population, the prevalence of anxiety and depression has been estimated, $35 \%$ and $16 \%$, respectively, using general health questionnaire (GHQ-28) ${ }^{(18)}$. Another study estimated the prevalence of anxiety and depression in a local Iranian population were 20.8 and $21 \%{ }^{(22)}$. Frequency of mood and anxiety disorders in IBS patients evaluated in several studies and Frequency of 5\%-15\% for depression and $16 \%-19 \%$ for Anxiety have been reported ${ }^{(12,21)}$. These values of depression and anxiety are significantly more than general population $^{(2,12,13)}$. While, using PSQI in IBS patients, the present study, have been dramatically calculated depression $(71 \%)$, anxiety $(76 \%)$, and stress $(79 \%)$. Discrepancy might be because of type of questionnaire and data collection but we suggest doing more studies about this subject.

Direct association of IBS and emotional disorders such as anxiety, depression, and stress causing sleep disturbances has been a controversial issue, some studies have proved that sleep disturbances was totally independent from the bowel problems especially $\mathrm{IBS}^{(32)}$. Here, the results were confirmed the independency of IBS and sleep quality.

This study has some limitations. First, we didn't have control group. Second, we didn't investigate objective sleep quality because there is no sleep lab in our university.

\section{CONCLUSION}

Our results confirm few previous studies and indicated that IBS patients have poor sleep quality and it is independent from the other factors. So we must consider and treat this problem in IBS patients. And also we must pay attention to depression more than the other psychological disorders in these patients because it can worsen sleep quality.

\section{ACKNOWLEDGEMENT}

We thank Kerman University of Medical Sciences for financial support of this research.

\section{Authors' contributions}

Baniasadi $\mathrm{N}$ and Dehesh MM suggested the initial conception, and gathered the information with the help of Hayatbakhsh Abbasi M and Oghabian Z. Mohebbi E did the data analysis and interpretation. Dehesh MM wrote the manuscript and then all the authors edited and confirmed the final version.

Baniasadi N, Dehesh MM, Mohebbi E, Hayatbakhsh Abbasi M, Oghabian Z. Avaliação da qualidade do sono e de depressão, ansiedade e estresse em pacientes com síndrome do intestino irritável. Arq Gastroenterol. 2017;54(2):163-6.

RESUMO - Contexto - A síndrome do intestino irritável (SII) é um dos transtornos gastrointestinais funcionais mais comuns, com dor abdominal crônica e alteração do hábito intestinal sem motivo orgânico aparente. Distúrbios do sono podem estar associados à SII. Objetivo - Avaliar distúrbios do sono e sinais de depressão, ansiedade e estresse em pacientes com SII. Métodos - Através de estudo analítico transversal, observou-se entre de novembro de 2013 e maio 2014, um total de 123 pacientes com SII, recrutados por amostragem aleatória simples. A SII foi diagnosticada usando-se os critérios de Roma III. Dados demográficos e básicos foram obtidos de todos os pacientes e o questionário de índice de qualidade de sono de Pittsburg foi utilizado para estimar a qualidade do sono; o questionário DASS (escala de depressão ansiedade stress) foi preenchido para depressão, ansiedade e stress. Resultados - A média de idade dos pacientes foi de $29 \pm 9$ anos, sendo 48 (39\%) do sexo masculino. Doze (10\%) tinham alguma doença associada. Nos subtipos de SII foram incluídos 38\% com diarreia, 42\% com constipação e 20\% de forma alternada. Do total, 87 (71\%), pacientes tinham depressão, o estresse foi observado em 97 (79\%) e 94 (76\%) tinham ansiedade. Setenta e seis (62\%) pacientes com SII tinham sono de má qualidade. A análise de preditores, empregados simultaneamente, demonstrou que o gênero, a doença associada e o tipo de SII não foram estatisticamente significantes. Por outro lado, depressão $(P=0,034, \mathrm{OR}=2,35)$, ansiedade $(P=0.011, \mathrm{OR}=3.022)$ e stress $(P=0,029, \mathrm{OR}=2,77)$ contribuíram significativamente no efeito da má qualidade do sono. Conclusão - A maioria dos pacientes com SII tem sono de má qualidade. Recomenda-se que o distúrbio do sono deva ser considerado e tratado nestes pacientes.

DESCRITORES - Síndrome do intestino irritável. Transtornos do sono-vigília. Depressão. Ansiedade. 


\section{REFERENCES}

1. Asgharimoghadam MA SF, Dibajnia P, Zanganeh J. Preliminary assessment of realibility and validity depression, anxiety, and stress scale (DASS) in nonclinical samples. Daneshvar Medical Journal. 2008;15:23-8

2. Bellini M, Tosetti C, Costa F, Biagi S, Stasi C, Del Punta A, et al. The genera practitioner's approach to irritable bowel syndrome: from intention to practice. Dig Liver Dis. 2005;37:934-9.

3. Benca RM, Okawa M, Uchiyama M, Ozaki S, Nakajima T, Shibui K, Obermeye WH. Sleep and mood disorders. Sleep Med Rev. 1997;1:45-56.

4. Budavari AI, Olden KW. Psychosocial aspects of functional gastrointestinal disorders. Gastroenterol Clin North Am. 2003;32:477-506.

5. Buysse DJ, Reynolds CF, Monk TH, Berman SR, Kupfer DJ. The Pittsburgh Sleep Quality Index: a new instrument for psychiatric practice and research Psychiatry Res. 1989;28:193-213.

6. Chang L. The role of stress on physiologic responses and clinical symptoms in irritable bowel syndrome. Gastroenterology 2011;140:761-5. e5.

7. Creed F. The relationship between psychosocial parameters and outcome in irritable bowel syndrome. Am J Med. 1999;107:74-80.

8. Cremonini F, Camilleri M, Zinsmeister AR, Herrick LM, Beebe T, Talley NJ. Sleep disturbances are linked to both upper and lower gastrointestinal symptoms in the general population. Neurogastroenterol Motil. 2009;21:128-35.

9. Elsenbruch S, Thompson JJ, Harnish MJ, Exton MS, Orr WC. Behavioral and physiological sleep characteristics in women with irritable bowel syndrome. Am J Gastroenterol. 2002;97:2306-14.

10. Francis C, Morris J, Whorwell P. The irritable bowel severity scoring system: a simple method of monitoring irritable bowel syndrome and its progress. Aliment Pharmacol Ther. 1997;11:395-402.

11. Heitkemper M, Jarrett M, Burr R, Cain KC, Landis C, Lentz M, Poppe A Subjective and objective sleep indices in women with irritable bowel syndrome. Neurogastroenterol Motil. 2005;17:523-30.

12. Janssens KA, Zijlema WL, Joustra ML, Rosmalen JG. Mood and anxiety disorders in chronic fatigue syndrome, fibromyalgia, and irritable bowel syndrome: results from the LifeLines Cohort Study. Psychosom Med. 2015;77:449-57.

13. Kanuri N, Cassell B, Bruce S, White KS, Gott BM, Gyawali CP, Sayuk GS. The impact of abuse and mood on bowel symptoms and health-related quality of life in irritable bowel syndrome (IBS). Neurogastroenterol Motil. 2016;28:1508-17.

14. Levy RL, Olden KW, Naliboff BD, Bradley LA, Francisconi C, Drossman DA, Creed F. Psychosocial aspects of the functional gastrointestinal disorders. Gastroenterology 2006; 130:1447-58

15. Longstreth GF, Thompson WG, Chey WD, Houghton LA, Mearin F, Spiller RC Functional bowel disorders. Gastroenterology. 2006;130:1480-1491.

16. Luscombe FA. Health-related quality of life and associated psychosocial factors in irritable bowel syndrome: a review. Qual Life Res. 2000;9:161-76.

17. Maxion-Bergemann S, Thielecke F, Abel F, Bergemann R. Costs of irritable bowel syndrome in the UK and US. Pharmacoeconomics. 2006;24:21-37.
18. Modabbernia M-J, Mansour-Ghanaei F, Imani A, Mirsafa-Moghaddam SA Sedigh-Rahimabadi M, Yousefi-Mashhour M, et al. Anxiety-depressive disorders among irritable bowel syndrome patients in Guilan, Iran. BMC Res Notes. 2012;5:112.

19. Moghaddam JF, Nakhaee N, Sheibani V, Garrusi B, Amirkafi A. Reliability and validity of the Persian version of the Pittsburgh Sleep Quality Index (PSQI-P). Sleep Breath. 2012;16:79-82

20. Morin CM, Gibson D, Wade J. Self-reported sleep and mood disturbance in chronic pain patients. Clin J Pain. 1998;14:311-4.

21. Mykletun A, Jacka F, Williams L, Pasco J, Henry M, Nicholson GC, Kotowicz MA, Berk M. Prevalence of mood and anxiety disorder in self reported irritable bowel syndrome (IBS). An epidemiological population based study of women. BMC Gastroenterol. 2010;10:88.

22. Noorbala A, Yazdi SB, Yasamy M, Mohammad K. Mental health survey of the adult population in Iran. Br J Psychiatry. 2004;184:70-3.

23. Nyrop K, Palsson O, Levy R, Von Korff M, Feld AD, Turner MJ, Whitehead WE. Costs of health care for irritable bowel syndrome, chronic constipation, functional diarrhoea and functional abdominal pain. Aliment Pharmacol Ther 2007:26:237-48.

24. Okami Y, Kato T, Nin G, Harada K, Aoi W, Wada S, et al. Lifestyle and psychological factors related to irritable bowel syndrome in nursing and medical school students. J Gastroenterol. 2011;46:1403-10

25. Orr WC. Gastrointestinal functioning during sleep: a new horizon in sleep medicine. Sleep Med Rev. 2001;5:91-101.

26. Robert JJ, Elsenbruch S, Orr WC. Sleep-related autonomic disturbances in symptom subgroups of women with irritable bowel syndrome. Dig Dis Sci. 2006;51:2121-7.

27. Rotem AY, Sperber AD, Krugliak P, Freidman B, Tal A, Tarasiuk A. Polysomnographic and actigraphic evidence of sleep fragmentation in patients with irritable bowel syndrome. Sleep. 2003;26:747-52.

28. Sperber AD, Tarasiuk A. Disrupted sleep in patients with IBS - a wake-up call for further research? Nat Clin Pract Gastroenterol Hepatol. 2007:4:412-3.

29. Spiller R, Garsed K. Postinfectious irritable bowel syndrome. Gastroenterology. 2009;136:1979-88.

30. Videlock EJ, Chang L. Irritable bowel syndrome: current approach to symptoms, evaluation, and treatment. Gastroenterol Clin North Am. 2007;36:665-85.

31. Whitehead WE, Palsson OS, Levy RR, Feld AD, Turner M, Von Korff M. Comorbidity in irritable bowel syndrome. Am J Gastroenterol. 2007;102:2767-76.

32. Wu J, Song Z, Xu Y, Zhang YM, Shen RH. [Probe into sleep quality in the patients with irritable bowel syndrome]. Zhonghua Nei Ke Za Zhi. 2010;49: 587-90

33. Yıldırım O, Alçelik A, Canan F, Aktas G, Sit M, İsçi A, Yalçın A, Yılmaz EE Impaired subjective sleep quality in irritable bowel syndrome patients with a Type D personality. Sleep Biol Rhythms. 2013;11:135-8. 